\title{
A data modeling conceptual framework for ubiquitous computing based on context awareness
}

\author{
Stenly Richard Pungus ${ }^{1,3}$, Jamaiah Yahaya ${ }^{1}$, Aziz Deraman ${ }^{2}$, Noor Hasrina Binti Bakar ${ }^{1}$ \\ ${ }^{1}$ Faculty of Information Science and Technology, Universiti Kebangsaan Malaysia, Malaysia \\ ${ }^{2}$ Faculty of Ocean Engineering Technology and Informatics, Universiti Malaysia Terengganu, Malaysia \\ ${ }^{3}$ Fakultas Ilmu Komputer, Universitas Klabat, Indonesia
}

\section{Article Info}

Article history:

Received Jan 21, 2019

Revised Apr 18, 2019

Accepted Jun 10, 2019

Keywords:

Context awareness

Data modeling

Ubiquitous computing

\begin{abstract}
This paper introduces a framework for data modeling to support ubiquitous computing based on context-awareness. Data always grow in term of volume, variety, velocity, and value. The problem arises when it grows exponentially. Consequently, data is anywhere and requirements change in early data definitions then data design become not as the plan. Therefore, suitable approach with new paradigm and methods of data modeling needs to be enhanced to solve the problems in the real world. Data model must consider the active object that related to each other. Any objects may interact with each other in a ubiquitous way and recorded in digital technology. Sensors, actuator devices, and radio frequency identification technology may support communication between objects through ubiquitous computing. The data model in Ubiquitous Computing needs to restructure to become active and dynamic. Ubiquitous computing is a model that enable all objects around the people to communicate and invisible. In order to support this paradigm, a new perspective of how data are designed and stored on each object is needed. Furthermore, using ubiquitous computing, the pervasive network can request and response information, which means the devices may communicate and has the initiative to solve a problem without human intervention. Human wants more intelligence objects. Therefore, more sensors and memory are required. Data structures need to enhance or embedded into any devices that interact with the human.
\end{abstract}

Copyright (c) 2019 Institute of Advanced Engineering and Science. All rights reserved.

\section{Corresponding Author:}

Stenly Richard Pungus,

Faculty of Information Science and Technology,

National University of Malaysia,

43600 Bangi, Selangor, Malaysia.

Email: stenly.pungus@unklab.ac.id

\section{INTRODUCTION}

The growth of the world of information and communication technology, particularly the field of computing happens so rapidly. Computers have advanced beyond the desktop into many parts of everyday life [1]. The distribution and use of current information and communication technologies (ICT) are considered to be the prerequisites nowadays for vibrant profitable growth and future possibility in global competition [2]. There exists a new paradigm that human will connects with the machine, living thing embodied physically with sensors, memory, and processors or smart objects, that may be called the Ubiquitous Computing, Internet of Thing (IoT), pervasive computing, or ambient computing, makes human interaction with machines and smart object getting closer. Therefore, humans can rely on machines to perform computation without human intervention. Each instance of a connected object in a network can perform the computation. Subsequently, this shifting paradigm can change the way data modeling today. 
Data modeling is the process to capture the reality of the world [3]. According to Watson, the critical issue in data modeling is the process to identify the entities and correct relationship among them, not the representation. Similarly argued by Peter Chen (1976) a data model (Entity Relationship diagram) includes some of the essential semantic information about the real world. Consequently, any representation from any data model is not the issue, but the ability to capture the reality. Furthermore, the world is beholding the delivery of an innovative computing paradigm that promises to have an insightful result on the way users collaborate with computers, devices, physical spaces, and other people. This innovative technology, called ubiquitous computing, envisions a world where embedded processors, computers, sensors, and digital communications are inexpensive commodities that are available everywhere [4]. Thus, this phenomenon will result in the complexity of the data model for each entity or objects.

This research motivated by relationship things in the real world. Generally, in order to understand such a relationship a model is required. Therefore, data modeling goal is to produce a data model that has high impact and useful life of the system [5]. Besides, the computing paradigm also changes. Objects in the real world are connected with network, sensors and embodied with computation process, data structure is not stored in a server but distributed in each object. Objects may respond and request based on context-aware.

Every day, objects are becoming smart objects, which are linked together into networks, react to their environment, and interact with their users [2]. The human creates objects more intelligence. Objects become intelligence when they have sensors. Objects that interact with human needs memory and sensors to communicate. Memory structure needs to enhance or embedded into any devices that interact with the human to store activities. Sensors will identify, measure, compute the property of data that received, and response to any object need it.

Objects in the real world that connects with the human may communicate through sensors. The data objects need further analysis to more detailed and structured to support its environment in the future. The real world is spotted and represented in a conceptual model then converted into a logical structure for a database. This is revealed in prescriptive methods and is the dominant assumption in most studies. Moreover, data modeling is also described as a type of design with negotiable requirements, a creative process, and many workable solutions [6].

According to [7], it is challenging tasks to migrate from the legacy system or application to service oriented. It requires the adaptation of the legacy interface to the interaction paradigm of web services or service oriented. Data communication between the legacy platform and the new emerging platform is the main reason for integration. However, if the legacy platform is not able to fulfill the data design requirement since its design with native code or primitive way or a different platform, then the data model needs to be refined in the context of its structure, data definition, format, and security. Consequently, all data in the legacy platform should be migrated to the new platform with new data model representation but the same high-level abstraction. There is one perspective from Jamaiah et.al [8] supported by [9] that to prolong the life of a system or software then anti-ageing activities need to be conducted, or software ageing can be suspended by classifying factors that influence and accelerate the ageing process. Those anti-ageing factors are functional, human, environment and product profile.

When the parameter is known then objects in daily life can be programmed. It is a challenge to program the connected objects. For the things that are assumed as an entity or object which can be coded as an instance, coding such objects' parameter, properties, behavior, and the metadata is possible. It is a challenge for a data scientist to refine again of how ones define the data object for the real world and computing activities. Objects in the real world can be programmed, but it should add some sensors that supported with data structured which may communicate or do the data transfer between objects.

\section{DATA MODELING PROBLEMS}

Database design is the process from a plan to become a real data model. The data model contains all the needed logical and physical design choices and all the parameters required to generate a design in a data definition [6]. A good design of a data is a challenge. Data modeling for database creation has commonly been considered to be a descriptive process $[10,11]$. In recent years, database systems and database design technology have encountered significant evolution [12]. The meaning of evolution in data design is a gradual development of data design to become better. Data modeling have been changed over time start with hierarchy data model, network data model, relational data model, and object-oriented data model. Each data object will have related to time and space and what object it may interact. However, computing thing such as hardware, software, network, and infrastructure are being connected with the things (human, environment, animal, plants, objects). The problem is how to model the connection between the user and those things. The researcher found several notation or methods are using now. There are data modeling notation with 
IDEF1X [13-15], CROW's by Richard Baker [16], Unified modeling language UML by OMG [17], Role Activity Diagram (RAD), Resources-Event-Agent-Location (REAL) [18], Extended Markup Language (XML) [19]. These data modeling techniques still have a limitation to modeling a data object within a context-awareness. IDEF, CHEN and CROW's Notation focus on data properties, UML focus on behaviors of its object, RAD focus on activities roles and REAL focus on events and locations and according to Kamsuriah and Reduan [19] there is no standard for XML data type and the method to map data from XML to relations is yet to be defined.

According to Chellappan, Mok and Reinsel [4, 20, 21] data comes from sensors used to gather shopper information, social media posts, digital pictures, and videos, purchase transaction, and cell phone GPS. Data in computer science described as raw materials or facts that collected together for reference and analysis. Raw materials mean it needs to process further to get insight that has values for organizations and facts needs to analyze to become information for decision making. Data generally created from text, audio, video, image, sensors. Furthermore, according to Mohammad and Kamsuriah, currently, organizations are flooded with several types of unstructured data such as e-mail, images, reports, maps, charts, publications. Thus, an effective and efficient business model of these data could help in decision making [22]. Data are represented to understand the real world by doing the analysis. However, data is not as simple as it looks. Data from the real world is growing exponentially [23]. A vast amount of data is collected from all media in particular storage. How big the data depend on its size, complexity, speed processing of the data related to other entity to provide a high quality of information. Consequently, data are anywhere with structured data, semi-structured data, unstructured data $[24,25]$. The impact is data requirements always change, platforms for data processing change, software architecture change. It is a challenge to manage the data with suitable data modeling techniques. Furthermore, data modeling is confronting a new challenge as a database design not only contains conventional relational databases but newer NoSQL databases managing significant amounts of unstructured data [26]. The literature on this subject covers several data modeling perspectives from, West, Rock and Evans, Good Child, Watson, and Franca. Table 1 summaries the perspectives of data modeling.

Table 1. Data modeling perspectives

\begin{tabular}{|c|c|c|c|}
\hline Author & Definition & Domain & Perspective \\
\hline West and Fowler [27] & $\begin{array}{l}\text { Data modeling is the first step in } \\
\text { database }\end{array}$ & Database design & $\begin{array}{l}\text { Conceptual, Logical, } \\
\text { Physical }\end{array}$ \\
\hline Rock and Evans [28] & $\begin{array}{l}\text { Data modeling is the study of what } \\
\text { data the business needs to enable } \\
\text { these activities to be complete }\end{array}$ & Business & Study, Activities \\
\hline Good Child [29] & $\begin{array}{l}\text { Data modeling deals with the process } \\
\text { of discretizing spatial variation. } \\
\text { However, it sometimes misleads to } \\
\text { the data structure }\end{array}$ & Geospatial & $\begin{array}{l}\text { Data Spatial, Data Structure. } \\
\text { (Array, Queue, Stacketc.) }\end{array}$ \\
\hline Watson [3] & $\begin{array}{l}\text { Data modeling captures the entities } \\
\text { and correct relationship }\end{array}$ & Education & $\begin{array}{l}\text { Understanding is more } \\
\text { important than } \\
\text { representation }\end{array}$ \\
\hline Franca [30] & $\begin{array}{l}\text { Data modeling is a parallel process } \\
\text { within analysis and design }\end{array}$ & Practical Database. NoSQL & Flexibility and Scalability \\
\hline
\end{tabular}

\section{MODELING BASED ON CONTEXT-AWARENESS}

This paper will propose a framework for ubiquitous computing domain that connects objects based context-awareness. This paper plans to leverage the data model with context based. The system already has the information to support the context. Furthermore, the system becomes intelligent, understand the data and situation on the particular time, location or any information that support the current activities.

According to Dey and Abowd [31] define context as any information that can be used to characterize the situation of an entity. An entity is an object, person, and place. It also may be any object that may be described with the simple abstract data type (ADT) that is considered relevant to the interaction between a user and an application, including the user and application themselves. To sum up, the context makes an entity, object or instance from a type have meaning.

Dey and Abowd in 2000 define context-awareness more generally:

"A System is context-aware if it uses context to provide relevant information and/or services to the user, where relevancy depends on the user's task."

Context-aware computing is a mobile computing paradigm in which applications can discover and take advantage of contextual information (such as user location, time of day, nearby people and devices, and user activity) [32]. Moreover, the field of context-aware computing already growing rapidly and sensors 
is the key of context awareness system. Contextual information captured by sensors depend on the type information to acquired such as location, time, near object, activities, temperature. Meanwhile, Ubiquitous Computing technologies become more mobile, distributed and executed by varying context [33]. Therefore, context awareness is a main feature of Ubiquitous systems to execute a particular task of an object.

According to Teorey, context awareness is a key factor for new applications in the area of ubiquitous computing [34]. Context is about bringing something right in the right place, right person, the right situation, right action and right time. The circumstance or situation must be relevant to the action or event. An action process or event will do something to achieve a purpose. Understood means, there are entities or objects that have sensors to receive input or message and translated as requested. Context is more important than content. Furthermore, the term of context at the beginning related with location [35]. Context with awareness may be defined as all entities or objects around us that have the intelligence to understand the location and how the entities reacted with the input around the environments. Typically, each entity must have complete properties to support data quality processing. According to [36] there are four main quality attributes. The attributes are usability, accessibility, compatibility, and functionality that need to be more considered. Objects must have complete behaviors to support logic processing. Awareness is knowledge or perception of a circumstance or facts.

To be concluded, context awareness is an important component in the data modeling and plays a key role in Ubiquitous Computing (ubicomp). Thus, this research aims to propose a data modeling framework for ubicomp based on context awareness. This framework will help the practitioner to find the way to get the properties and the behaviors of the object in the development of ubiquitous application domain.

\section{RELATED WORKS}

From previous study many researchers trying to develop infrastructures such as frameworks or applications to solve some particular problems in the Ubiquitous computing field. However, there are still some limitations of guidelines or frameworks for modeling an object in a particular domain of the problem. Choi Kim et al. [37] defined the contextual dependency among contextual information and proposed the context-aware ERM design methodology based on the contextual dependency. Also, this paper constructed a relational schema from the derived ERD, and they introduced the prototype of context-aware leisure recommendation systems, the limitation of their work is the representation in the ERD model. Later, Mohan and Singh (2013) [38] proposed a formal model based on ontology they argued ontological models have clear advantages regarding support for interoperability, heterogeneity, and representation of complex relationships and dependencies among context data.

Weiser states [39]: “Ubiquitous computing is a vision of computing power 'invisibly' embedded in the world around us and accessed through intelligent interfaces..." In 2015 this statement supported by Azizul et al. that Ubiquitous computing is the third era of modern computing. Riley [40] defined Ubiquitous computing is a new paradigm where technology becomes virtually invisible in our lives, agree with Weiser's vision. Dey and Abowd [31] define context as any evidence that can be used to describe the condition of an object. Furthermore, Chen and Kotz support that context awareness a key factor for new applications in the area of ubiquitous computing.

\section{DATA MODELING CONCEPTUAL FRAMEWORK FOR UBIQUITOUS COMPUTING BASED ON CONTEXT AWARENESS}

As found through the literature review on data modeling, ubiquitous computing and context awareness the researcher construct a conceptual framework of the research. Figure 1 shows the conceptual framework. This conceptual framework will produce a data model based on Context Awareness for Ubiquitous Applications. It works as follows: Firstly, this model identifies the key elements of Ubiquitous Computing. Then, it identifies the domain of applications or problems to be solved. Afterward, things, entities, objects are identified, including the data types. Secondly, the relationship between entities is analyzed to determine whether there exists any value of other objects within an entity. Thirdly, environment functions are evaluated, how an entity or object behave to its environment. This process involves sensor(s) and (or) actuator(s). Then, by using ontology the entities properties or attributes, and functions are described to yield a specific data model based on context awareness to solve the domain problem previously defined. 


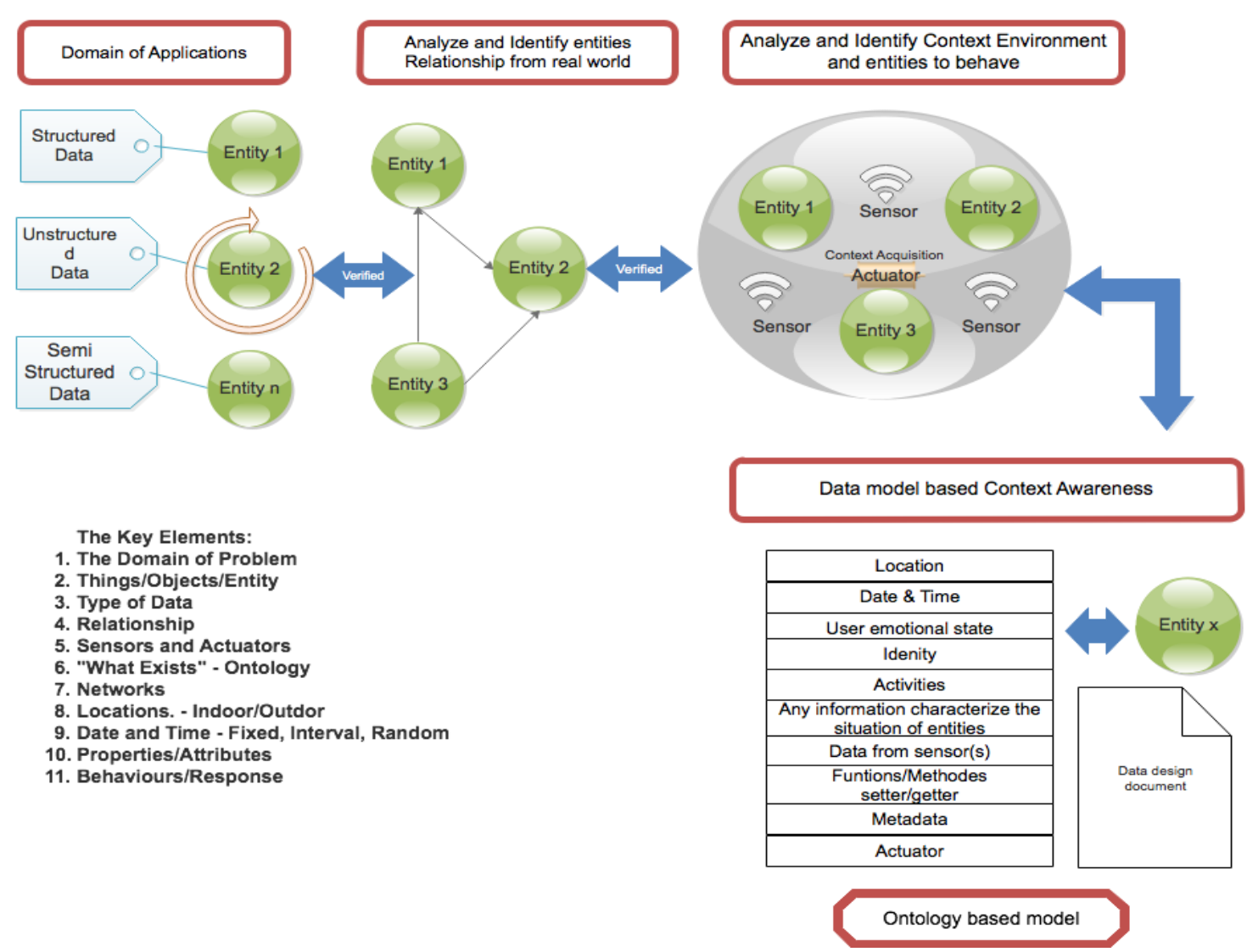

Figure 1. Proposed data modeling conceptual framework for ubicomp based on context awareness

\section{CONCLUSION AND FUTURE WORK}

This paper describes the findings of previous studies related to data modeling techniques, ubiquitous computing and context awareness. From the previous studies, the researcher found that some of the infrastructures like frameworks and applications (prototypes) as a proof of a concept have been built. However, there is a lack of studies focuses on data modeling framework for ubiquitous computing particularly. Therefore, a conceptual framework of data modeling for Ubicomp is based on Context Awareness is proposed. It is believed to be more represent the problem of the real world. To advance the contribution of this paper, researchers plan on keeping up with the advances of ubicomp and developing a prototype to study its impact on a particular domain problem. Researchers also plan on proposing a verification and validation for this data modeling framework for ubicomp based on context-awareness.

\section{ACKNOWLEDGEMENTS}

This work is supported partly by The Arus Perdana Grant of UKM (AP-2017-005/3). The authors also gratefully thank to Faculty of Information Science and Technology, Universiti Kebangsaan Malaysia and Faculty of Computer Science, Universitas Klabat for supporting this research.

\section{REFERENCES}

[1] A. Schmidt, "Ubiquitous Computing - Computing in Context," Environments, pp. 312, 2003.

[2] J. Sen, "Ubiquitous Computing: Potentials and Challenges," Proc. Int. Conf. Trends Adv. Comput. Eng., pp. 1323-1346, 2010.

[3] R. T. Watson, "The Essential Skills of Data Modeling," J. Inf. Syst. Educ., vol. 17, pp. 39, 2006.

[4] D. Reinsel, et al., "StorageNewsletter » Total WW Data to Reach 163ZB by 2025," 2017, [Online], Available: https://www.storagenewsletter.com/2017/04/05/total-ww-data-to-reach-163-zettabytes-by-2025-idc/.

[5] G. C. Simsion and G. C. Witt, "Data modeling essentials," Morgan Kaufmann Publishers, 2005.

[6] G. Simsion, et al., "Data modeling: Description or design?" Inf. Manag., vol. 49, pp. 151-163, 2012.

[7] G. Canfora, et al., "Migrating interactive legacy systems to Web Services," Proc. Eur. Conf. Softw. Maint. Reengineering, CSMR, 2006, pp. 24-33. 
[8] J. H. Yahaya, et al., "Perspective and perception on software ageing: The empirical study," 10th International Conference on Computer Science and Education, ICCSE 2015, 2015.

[9] Z. H. Abdullah, et al., "Towards anti-Ageing model for the evergreen software system," Proceedings - 5th International Conference on Electrical Engineering and Informatics: Bridging the Knowledge between Academic, Industry, and Community, ICEEI 2015, 2015.

[10] R. Jacobson, "2.5 quintillion bytes of data created every day. How does CPG \&amp; Retail manage it? - IBM Consumer Products Industry Blog," Ibm, 2013, [Online], Available: https://www.ibm.com/blogs/insights-onbusiness/consumer-products/2-5-quintillion-bytes-of-data-created-every-day-how-does-cpg-retail-manage-it/.

[11] J. Flanders and F. Jannidis, "Data Modeling,” A New Companion to Digital Humanities, pp. 229-237, 2015.

[12] C. Mancas, "Conceptual Data Modeling and Database Design: a Fully Algorithmic Approach," Apple Academic Press, vol. 1, 2016.

[13] Computer Systems Laboratory of the National Institute of Standards and Technology (NIST), "IDEFØ - Function Modeling Method - IDEF," 1993, [Online], Available: http://www.idef.com/idefo-function_modeling_method/.

[14] M. Blaha, "Patterns of data modeling, Routledge, 2010.

[15] P. P. S. Chen, "The entity-relationship model--toward a unified view of data," ACM Trans. Database Syst., vol. 1, pp. 9-36, 1976.

[16] R. Mamayev, "Data modeling of financial derivatives," Apress, 2014.

[17] G. C. Simsion and G. C. Witt, "Data Modelling Essentials Third Edition," Elsevier Ltd, 2005.

[18] D. E. O. Leary, "Modeling Time in REA / REAL Databases : Planning and Availability Modeling Time in REA / REAL Databases : Planning and Availability," pp. 1-24, 1999.

[19] K. Ahmad and R. Samad, "Semantic based mapping from XML to relations," Proceedings - ICIDT 2012, 8th International Conference on Information Science and Digital Content Technology, 2012.

[20] J. Mok, "Studying a ubiquitous learning and computing environment," Ubiquitous Learn., vol. 1, pp. 49-56, 2009.

[21] V. Chellappan and K. M. Sivalingam, "Security and privacy in the Internet of Things," Internet of Things: Principles and Paradigms, pp. 183-200, 2016.

[22] M. F. Abdullah and K. Ahmad, "Business Intelligence Model for Unstructured Data Management," 5TH International Conference on Electrical Engineering and Informatics 2015, 2015.

[23] IBM, 4-Vs-of-big-data, IBM, 2015.

[24] A. Fallis, “The four V's of big data," Big Data, vol. 53, pp. 1689-1699, 2013.

[25] Y. Demchenko, et al., "Architecture framework and components for the big data ecosystem," J. Syst. Netw. Eng., pp. 1-31, 2013.

[26] G. Paramitha, "Data Modeling Trends in 2018 Data Modeling Trends in 2018 - DATAVERSITY," DATAVERSITY, 2018, [Online], Available: http://www.dataversity.net/data-modeling-trends-2018/.

[27] M. West, "Developing high quality data models," 2011, [Online], Available: http://www.google.com/books?hl=pt$\mathrm{PT} \& 1 \mathrm{r}=\& \mathrm{id}=\mathrm{y} \_\mathrm{gSxWkCXtYC} \& \mathrm{i}=\mathrm{fnd} \& \mathrm{pg}=\mathrm{PP} 2 \& \mathrm{dq}=\% 22 \mathrm{enterprise}+$ architecture $\% 22+\% 2 \mathrm{~B}+\% 22 \mathrm{model}+$ analysis $\% 22 \&$ ots=AbcPQWlbhi\&sig=f-bL71hXq2O2UR30dlEdRYzKx6A.

[28] R. J. Muller, "Database design for smarties: using UML for data modeling," Morgan Kaufmann, 1999.

[29] G. Despotou, "Introduction to Modelling," 2007.

[30] W. da R. Franca, "MongoDB Data Modeling," 2014.

[31] J. Krumm, “Ubiquitous Computing Fundamentals," CRS Press, 2010.

[32] G. Chen and D. Kotz, "A Survey of Context-Aware Mobile Computing Research," Dartmouth Comput. Sci. Tech. Rep., vol. 3755, pp. 1-16, 2000.

[33] S. S. Wenzl and M. Strembeck, "Modeling context-aware RBAC models for business processes in ubiquitous computing environments," Proceedings - 2012 3rd FTRA International Conference on Mobile, Ubiquitous, and Intelligent Computing, MUSIC 2012, pp. 126-131, 2012.

[34] T. Teorey, et al., "Database Modeling and Design,” Fourth. morgan kaufmann, 2006.

[35] O. Kwon, et al., "Context-aware multi-agent approach to pervasive negotiation support systems," Expert Syst. Appl., vol. 31, pp. 275-285, 2006.

[36] J. Yahaya, et al., "Software process model for dynamic website development towards quality product," J. Telecommun. Electron. Comput. Eng., vol. 9, pp. 6, 2017.

[37] D. Choi, et al., "Conceptual data modeling for realizing context-aware services," Expert Syst. Appl., 2012.

[38] P. Mohan and M. Singh, "Formal Models for Context Aware Computing," J. Comput. Appl. Technol., vol. 2, pp. 53-58, 2013.

[39] M. Weiser, "Hot topics-ubiquitous computing," Computer (Long. Beach. Calif)., vol. 26, pp. 71-72, 1993.

[40] M. Riley, "Ubiquitous Computing: An Interesting New Paradigm," 2017, [Online], Available: http://project.cyberpunk.ru/idb/ubicomp_interesting_new_paradigm.html. 


\section{BIOGRAPHIES OF AUTHORS}

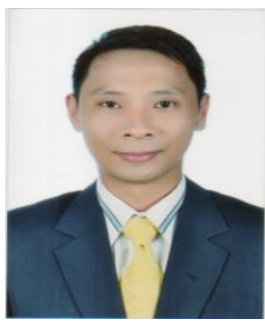

Stenly Richard Pungus is a lecturer of software engineering and database at Faculty of Computer Science, Universitas Klabat. He received his bachelor degree in computer science from Universitas Klabat, Manado, Indonesia and Master degree from Institut Teknologi Bandung, Indonesia. He currently as Ph.D candidate at Faculty of Information Science and Technology, National University of Malaysia. His research and teaching interests are in at software engineering, data modeling, service oriented architecture and mobile computing. He has published research papers in several journals and proceedings.

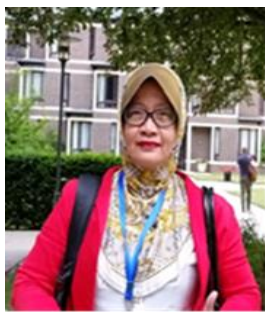

Dr. Jamaiah Yahaya is the Associate Professor at Faculty of Information Science and Technology (FTSM), The National University of Malaysia (UKM) since July, 2011. Prior that she worked as a senior lecturer in School of Computing, Northern University of Malaysia (UUM) and a system analyst at University of Science Malaysia (USM). Her bachelor degree was Bachelor of Science in Computer Science and Mathematics from University of Wisconsin-La Crosse, USA (1986), Master of Science in Information System from University of Leeds, UK (1998), and PhD in Computer Science from The National University of Malaysia (UKM) (2008). Her PhD thesis was the development of software certification model and later, she continued her PhD research as a post-doctoral fellow in UKM (2008). She was appointed in a few management posts such as the head of PhD program and acting Deputy Dean of Academic in FTSM, UKM. Her research interests are software quality, software development and management, and software assessment and impact. She is an active researcher with more than 100 publications in the international journals and proceedings for the last 5 years.

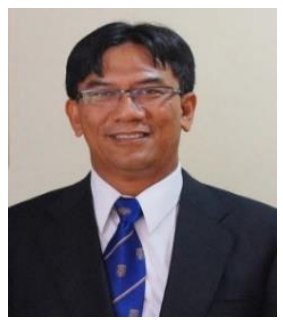

Prof Dato' Dr. Aziz Bin Deraman is a Senior Professor of software engineering in Faculty of Ocean Engineering Technology and Informatics, University Malaysia Terengganu (UMT), Malaysia. He received his Bachelor of Science from Universiti Kebangsaan Malaysia (UKM) (1982), MSc in Computer Science from Glasgow University (1984) and PhD in Computer Science from UMIST, Manchester, UK (1992). His research interests include software process, software certification and management, and ICT strategic planning. He has held various academic administration positions such as Dean of the School of Informatics and Applied Mathematics, UMT and Vice Chancellor of University Malaysia Terengganu (UMT). He has published more than 200 publications in both local and international journals and proceedings, and successfully supervised more than $50 \mathrm{PhD}$ and master graduates.

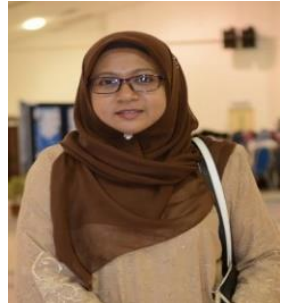

Dr. Noor Hasrina Binti Bakar is a senior lecturer at Faculty of Information Science and Technology at National University of Malaysia. Her research interest are in at requirements engineering, software reuse and empirical software engineering. She has published research papers in various journals and proceedings. 